\title{
Arqueología: una reflexión en torno a la producción académica en el Seminario de Historia Rural Andina
}

\author{
Amparo Alí Chávez \\ amac.arqueologia@gmail.com \\ Universidad Nacional Mayor de San Marcos \\ Facultad de Ciencias Sociales
}

\begin{abstract}
SUMILLA:
Los estudios multidisciplinarios del Seminario de Historia Rural Andina han promovido el conocimiento en temas arqueológicos andinos y amazónicos, siendo Pacopampa (Chota, Querocoto, Cajamarca) un eje principal de estudio dentro del área de la arqueología desde mediados de la década de 1960. Ello ha permitido dar alcances sobre la problemática cronológica del período Formativo, además de la descripción, prospección y excavación del sitio arqueológico. Desde la década de 1970 hasta la actualidad las publicaciones de diferentes arqueólogos han permitido conocer diferentes investigaciones sobre el arte (iconografía, rituales e instrumentos musicales) y la economía prehispánica (optimización de la agricultura colonial y el uso de sistema hidráulico prehispánico asociado a humedales en la costa peruana).

Palabras-clave: Arqueología Peruana; Pacopampa; Formativo; Seminario de Historia Rural Andina.
\end{abstract}

\section{Archaeology: reflections about the scientific contribution of the Seminario de Historia Rural Andina}

\begin{abstract}
:
The multidisciplinary approach of the Seminario de Historia Rural Andina had encouraged the study of Andean and Amazonian archaeology, and the archaeological project of Pacopampa has remained emblematic since the decade of 1960. As a result significant data about its chronology and the cultural components of this Formative period site have been produced so far. In addition, other studies have provided valuable data about prehispanic art, economics and water management on the coast. Keywords: Peruvian Archaeology; Pacopampa; Formative; Seminar of Andean Rural History.
\end{abstract}

\section{Introducción}

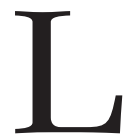

as investigaciones durante los primeros cincuenta años del Seminario de Historia Rural Andina (SHRA) han sido innumerables, realizando un trabajo multidisciplinario. Dentro de estas investigaciones, la Arqueología ocupa un lugar relevante en particular por el estudio del sitio arqueológico de Pacopampa (Chota, Querocoto, Cajamarca). A mediados de la década de 1960, Pablo Macera realizó una expedición a ese sitio con un grupo de estudiantes, hecho que dará inicio a nuevas investigaciones relativas al tema del período Formativo. Esta década es ade- 
más importante para la arqueología dado que existe una revaloración de las culturas prehispánicas y la creación de diferentes instituciones como el Instituto Tecnológico de Arqueología por Julio C. Tello dedicado al estudio de la Costa Sur.

Las investigaciones arqueológicas en las primeras décadas del SHRA, además de Pacopampa, cubre investigaciones en Puno, Junín, Cusco y Lima. La perspectiva marxista planteada por arqueólogos nacionales y extranjeros aplicada a la comprensión de las culturas prehispánicas tiene un lugar importante, hecho que se pude evidenciar en parte con la colección Lecturas Emilio Choy dirigida por Jaime Miasta.

\section{Pacopampa}

En el sitio Arqueológico de Pacopampa se realizaron diversas expediciones. La primera de la que se tiene noticia fue hecha por Rafael Larco Hoyle en 1939, quien encontró cerámica, husos y piedras labradas, algunos de los cuales fueron descubiertos por los lugareños en las chacras aledañas al sitio monumental. Los monolitos recolectados se encuentran actualmente en el Museo Larco Herrera (Lima), y otro está en la plaza de San Pedro de Pacopampa.

En 1966, Pablo Macera, director del SHRA, realizó una visita al sitio de Pacopampa. Su alumno Saúl Cieza lo llevó a conocer la zona arqueológica. Macera entusiasmado por las posibilidades de este sitio lleva a cabo una serie de actividades para iniciar la exploración e investigación de la zona. En ese sentido, comenzó una serie de gestiones infructuosas ante el Ministerio de Fomento y la Presidencia de la Republica. Pero a cambio recibió la colaboración decisiva de don Jorge C. Muelle (Asesoría del Proyecto), Emilio Choy (donativo para la compra del terreno del sitio), Víctor Tantaleán (diputado, desde el Congreso gestionó las partidas), así como la financiación de las dos temporadas de excavaciones arqueológicas por la Universidad Nacional Mayor de San Marcos (UNMSM). Asimismo, invitó a los arqueólogos del Museo Nacional de Antropología y Arqueología para que lleven a cabo investigaciones en Pacopampa, Agua Blanca y Pandanche. Al mismo tiempo de hacer estas gestiones, Macera estableció contactos con vecinos, profesores y autoridades locales con el objeto de hacerlos partícipes en este proyecto.

El motivo de tan ardua labor de parte de Macera fue el ejecutar un plan piloto de investigación multidisciplinario con dos núcleos de trabajo: Pacopampa y una granja experimental en Pagaybamba. Ambos servirían como centros permanentes de adiestramiento, el primero para los alumnos de Arqueología y el segundo para los de Veterinaria de la UNMSM. Además se incluyó a los alumnos del área de Educación de la UNMSM para que participasen en programas nacionales de alfabetización; hecho importante, ya que gracias a ello se logró un gran avance educativo en la localidad. Así, durante los años 1975 a 1980, la universidad no solo desarrolló investigaciones arqueológicas, sino que dentro de su plan de proyección a la comunidad, realizó una amplia difusión de los resultados de las investigaciones: se dieron charlas a los colegios, escuelas, agencias municipales y clubs deportivos, tanto a escala local como regional dentro de la provincia de Chota, con ello se logró la identificación con el patrimonio arqueológico de Pacopampa. ${ }^{1}$

Como puede verse en el cuadro 1 la importancia arqueológica de Pacopampa motivó varias investigaciones. $^{2}$

1 Morales 1996: 8-10.

2 Andazabal 2006: 17-18. Existen otros sitios investigados cerca de Pacopampa. El montículo Valderrama; Agua Blanca; Machaipungo; La Granja. De ello solo tenemos datos breves sobre patrones de enterramiento y, también, características de la 


\section{SEMINARIO DE HISTORIA RURAL ANDINA \\ INVESTIGACIONES ARQUEOLÓGICAS EN PACOPAMPA (1967-1985)}

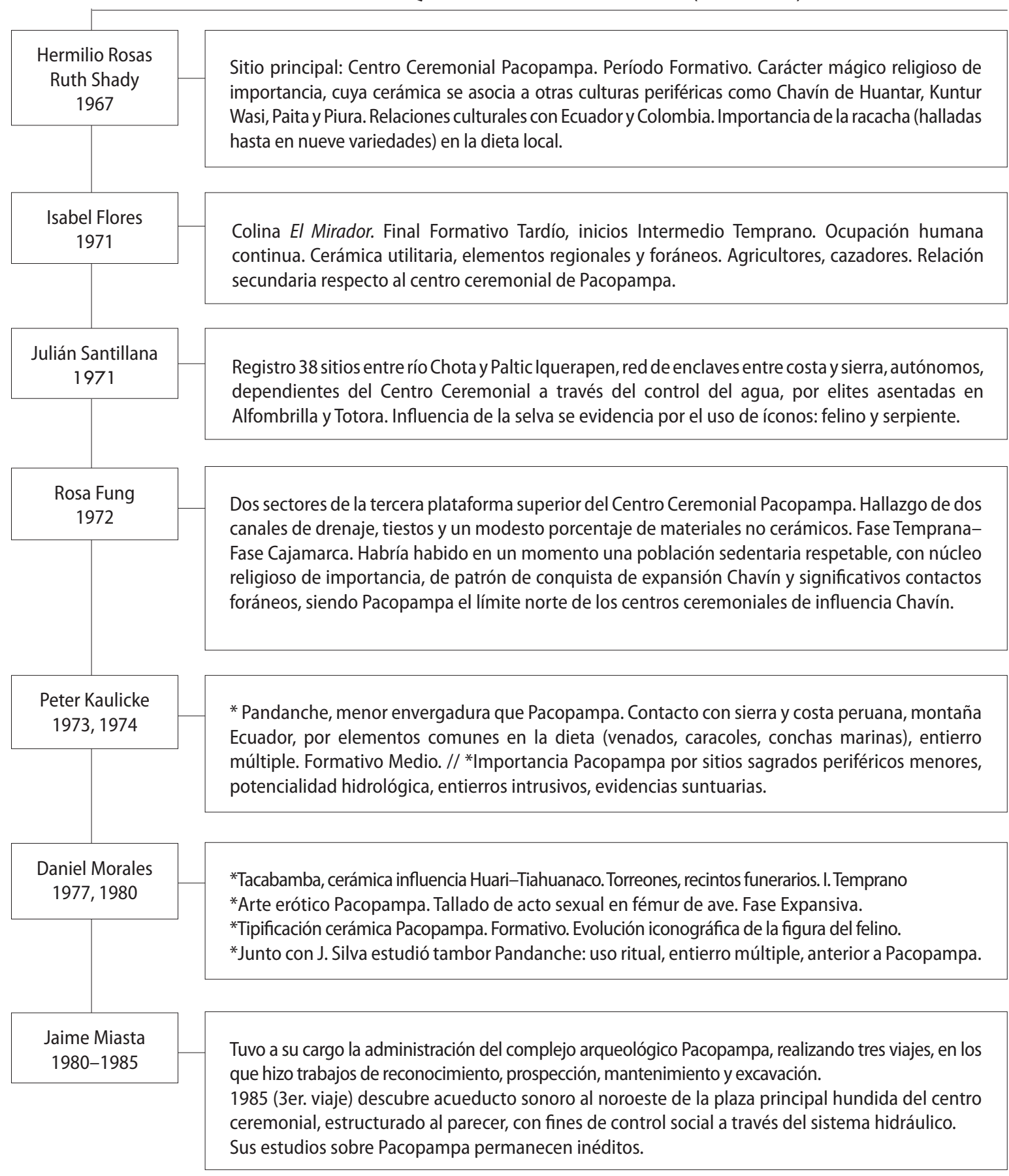

Cuadro 1. Cuadro esquemático de las excavaciones en Pacopampa. Andazabal, 2006. 
En el año 1967, los arqueólogos y colaboradores del SHRA, Hermilio Rosas y Ruth Shady ejecutaron excavaciones durante casi cuatro meses, identificando grandes muros, galerías subterráneas, plazas hundidas, escalinatas, columnas, cornisas, relieves y basurales pertenecientes al período Formativo. Años más tarde, Rosas y Shady, publican Pacopampa. Un centro formativo en la sierra norperuana (1970), un informe preliminar dentro de las actividades del SHRA, con el asesoramiento del entonces Director del Museo Nacional de Antropología y Arqueología Jorge C. Muelle. El objetivo del informe fue "trazar un esquema tentativo del desarrollo cultural durante el período Formativo en Pacopampa”, para ello presentaron una serie de antecedentes históricos y evidencias arqueológicas como estudios de la superficie, cortes estratigráficos, evidencias arquitectónicas, entierros, cerámica de fase Pacopampa, fase Pacopampa Chavín, artefactos de hueso y misceláneos.

Rosas y Shady, ubican al templo en la superficie delimitando su extensión de 600 a 200m. y una altura de $35 \mathrm{~m}$. sobre el nivel del piso de la primera plataforma. ${ }^{3}$ Luego, realizan un estudio detallado de la arquitectura encontrando tres plataformas, delimitando los muros A y B, además de entierros donde se hallan cerámicas de diferentes tipos de pasta, forma y decoración; entre otros datos importantes. Uno de los puntos de discusión que considero importante señalar es sobre la dieta alimenticia, las fases encontradas como la de Pacopampa y Fase Chavín, que sin lugar a duda era una fase que tenía relaciones culturales semejantes y diferentes en los estilos y la tipología. Uno de los aportes de Rosas y Shady fue el establecimiento de la cronología del sitio: la fase Pacopampa-Pacopampa (1200 a. C-800a. C) y la fase Pacopampa-Chavín (800 a.C).

En el año 1972, Rosa Fung con un grupo de estudiantes de arqueología de la UNMSM, durante 18 días, excavaron dos unidades, una de las cuales se ubicaba dentro de la plaza hundida y la otra cerca de la plaza de la plataforma superior hasta que lograron alcanzar suelo estéril. Las excavaciones a pequeña escala no permitieron aclarar aspectos de la configuración arquitectónica total del sitio. Sin embargo, las excavaciones y los análisis de los materiales recuperados permitieron establecer 6 fases constructivas en el complejo arqueológico (ab, c, d, e, f, gh). ${ }^{4}$

Fung correlacionó las fases de Pacopampa con otras culturas. La fase ab, la cual se caracteriza por presentar cerámica decorada con las líneas incisas cortantes y superficiales, tiene similitud con la fase Torrecita-Chavín descubierta en el valle de Cajamarca por los esposos Rechlen aunque la conexión de ambas culturas seria de tipo algo colateral y no directa. Al mismo tiempo, ella planteó la posibilidad de una influencia selvática como el origen y derivación de estas unidades estilísticas. ${ }^{5}$

En el año 1975, Isabel Flores y Julián Santillana, publican Excavaciones en el Mirador de Pacopampa, que contiene dos estudios preliminares. El primero, consiste en un estudio en la Colina, El mirador, realizado por Flores; describe los aspectos geográficos, además brinda una metodología de estudio que sería importante señalar: la exploración en el área, excavaciones y análisis de material cultural en el laboratorio. Por ende, gracias a su metodología se pudo delimitar durante sus excavaciones cuatro estratos, recuperando los materiales culturales como cerámica principalmente, que dio a lugar a varias tipologías de cerámica como Pacopampa gris inciso o estampado, Pacopampa rojo sobre crema, Pacopampa inciso cortante superficial, Pacopampa fileteado o con tiras aplicadas, Pacopampa escultórica o modelada, Pacopampa inciso

cerámica. Seki y Morales 2014: 8.

3 Rosas y Shady 1970: 11.

4 Seki y Morales 2014: 6.

5 Seki y Morales 2014: 7 . 
o banda superpuestas, cerámica rojo o negro sobre crema y cerámica Cajamarca. Además, se encontraron innumerables cerámicas sin clasificar. Asimismo, las técnicas en arquitectura son destacables, los artefactos líticos, entierros, entre otros. Otro dato curioso es la red de enclaves asentados en la costa y la sierra, cuyo poder se habría basado en el control del agua manejado por un sector de elite. Además, la influencia de ceja de selva se ve marcada en el uso de la iconografía del felino.

El segundo estudio es una prospección del sitio arqueológico de Pacopampa, de Julián Santillana. Los datos que presenta en cuanto a los patrones de asentamiento relacionados con las zonas ecológicas son valiosos, para tener información de distribución de los sitios arqueológicos de esta zona. Además, realiza una descripción Ecología del asentamiento, con ello relaciona las categorías con la racionalización climática elaborada por Pulgar Vidal. ${ }^{6}$ Sin embargo, existen algunas contradicciones sobre las zonas ecológicas planteada por Santillana y por Rosas y Shady. La zona quechua para Santillana abarca el área desde $1200 \mathrm{msnm}$ hasta $2200 \mathrm{msnm}$; la zona Jalca para Santillana está comprendida desde los 2200 msnm a más, la zona playa se encuentra entre 1000-1200 msnm.

En el año 1975, Peter Kaulicke, publica Pandanche un caso del Formativo en los andes de Cajamarca, que consiste en un informe de las investigaciones arqueológicas realizadas fuera del centro ceremonial Pacopampa, mediante las excavaciones en Pandanche (1973 y 1974), sitio en forma de un montículo con varias plataformas. Dichas excavaciones dirigidas por Kaulicke sacan a luz la etapa inicial de la elaboración de cerámica que corresponde a una época anterior al establecimiento del sitio Pacopampa. Así tenemos, que la fase Pandanche A pertenece al período inicial o fase temprana del período formativo. La fase Pandanche B corresponde a la fase PacopampaPacopampa y además, otras dos fases que pertenecen al Pacopampa Chavín del período Formativo Tardío y de la cultura Cajamarca del período Intermedio Temprano respectivamente.

Kaulicke, menciona la problemática del Formativo peruano estrechamente ligado con el concepto cultural Chavín, que surgió con el descubrimiento del sitio Chavín de Huántar por Julio C. Tello en 1919 y que desde entonces fue un estímulo constante para que los arqueólogos nacionales y extranjeros buscasen resolver el enigma de la cultura matriz de la civilización andina. ${ }^{7}$ Además, explicaría la amplia distribución de elementos relacionados en el área andina. Por ello, un dato relevante es la consideración de los términos Chavín o Chavín Clásico y Chavinoide, de los cuales se puede extraer quizás zonas culturales nucleares y marginales. Cabe señalar que el término Chavinoide puede explicar los elementos culturales influenciados por supuestos centros del Chavín clásico o elementos relacionados con aquellos pero anteriores a su cristalización cultural. ${ }^{8}$ En consecuencia, propone que sería importante relacionar las zonas nucleares con las zonas marginales.

Kaulicke, continúa con sus investigaciones y presenta El formativo en Pacopampa (1976) donde menciona la problemática de la iconografía Chavín, además de interrelacionar los datos arqueológicos, etnográficos e históricos. La preocupación por conocer el templo de Pacopampa y sus anexos serían posteriores al centro ceremonial de Pandanche, y da a conocer una posibilidad de una alimentación similar. Por último, el dato más resaltante es que el desplazamiento de Pandanche a Pacopampa habría estado asociado al desarrollo de una tecnología agrícola sofisticada que comprendería el maíz principalmente.

Flores y Santillana. 1975.

Kaulicke 1975: 5.

Kaulicke 1975: 6. 
En el año 1980, Daniel Morales Chocano realiza una serie de estudios en torno al sitio arqueológico Pacopampa. Excavó en Pandanche y Tacabamba, La Capilla y Pacopampa. La Capilla está dentro del centro ceremonial de Pacopampa y al costado del sitio B mirador. Morales, como resultado de estos trabajos, presentó una cronología alternativa: Pacopampa inicial, Pacopampa apogeo y Pacopampa expansivo. Aparte de la cronología, Morales ha contribuido al entendimiento del patrón de la ideología en la zona a través de los análisis de la iconografía de la cerámica. Entre sus libros, se encuentra El arte erótico de Pacopampa (1980), donde muestra el estudio iconográfico del arte en Pacopampa del fémur de un ave en el que se encuentra tallado un acto sexual natural, esta representación iconográfica corresponde a la fase expansiva de Pacopampa. Además, sería la evidencia más antigua del arte erótico del norte peruano, anterior a Vicus y Mochica. Muestra además la interacción interregional cultural entre el Ecuador (Cultura Chorrera), y el Perú (Cultura Chavín), donde lo erótico está asociado a la fertilidad de la tierra. En otro de sus libros, Dios felino de Pacopampa, (1980), se basa en los fragmentos de cerámica de Pacopampa, durante el formativo, dividida en tres fases de desarrollo, donde se muestra la evolución iconográfica de la figura del felino, este es ubicado en fase de apogeo, asociado a la sociedad de elite que tenían como idea religiosa la "divinidad felínica”, a su vez mantuvo el poder económico y logró el equilibrio entre las contradicciones hombre/naturaleza.

Además, Morales, como parte del Proyecto arqueológico Pacopampa, realizó una serie de viajes al sitio y en uno de sus informes nos presenta fotografías de algunos sectores de excavaciones y fragmentos de cerámica, donde muestra el estado de conservación de la arquitectura. Ello se tiene como registro fotográfico de las áreas expuestas al medio ambiente, recordando que serán afectadas al transcurrir los años.

Uno de los ejes más importantes de las investigaciones realizadas en el Sitio arqueológico de Pacopampa es sin lugar a duda la problemática que existía con la cronología. Sin embargo, como ya se ha mencionado, gracias al investigador y arqueólogo Daniel Morales, se ha podido definir un cuadro esquemático para correlacionar las fases y los tipos de cerámica establecidos por los diferentes arqueólogos y con ello facilitar la comprensión de las áreas excavadas. Por tanto, se evidencia lo siguiente:

- La fase Pacopampa inicial de Morales corresponde a la fase A de Pandanche planteada por Kaulicke.

- La fase Pacopampa apogeo de Morales corresponde a la fase Pacopampa AB de Fung y la fase Pacopampa Pacopampa de Rosas y Shady.

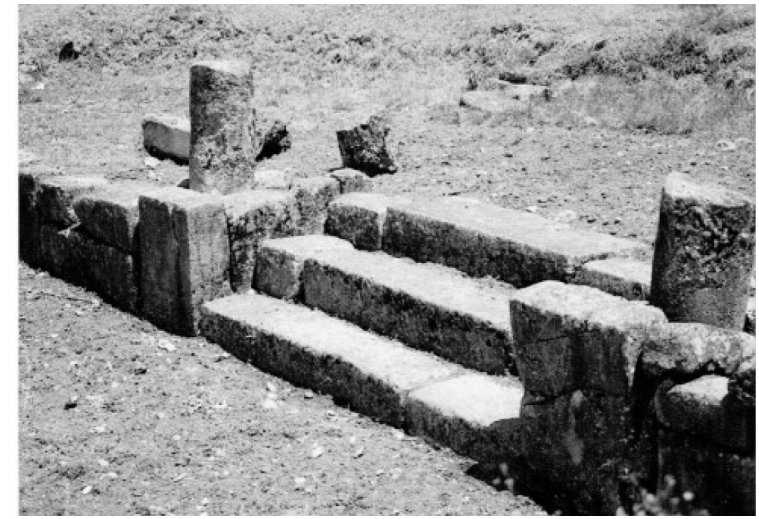

Fotografía 1. Escalinatas con columnas de la tercera plataforma. Fuente: Daniel Morales. 1996.

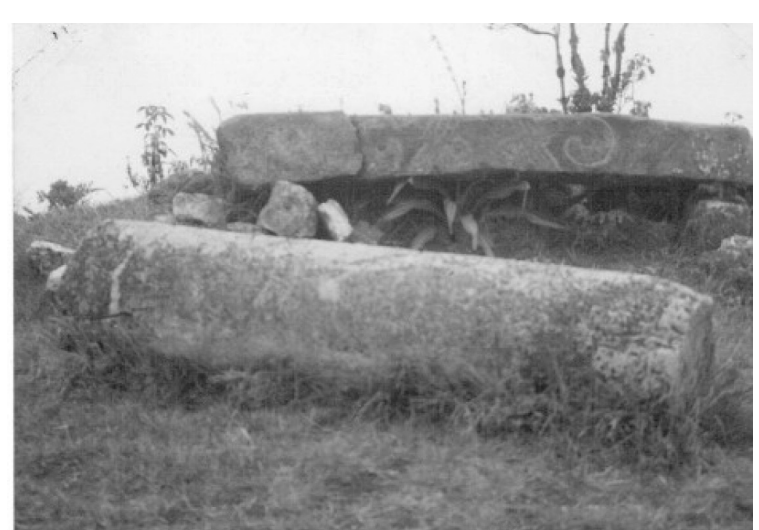

Fotografía 2. Dintel y columna de la tercera plataforma. Fuente: Daniel Morales. 1996. 


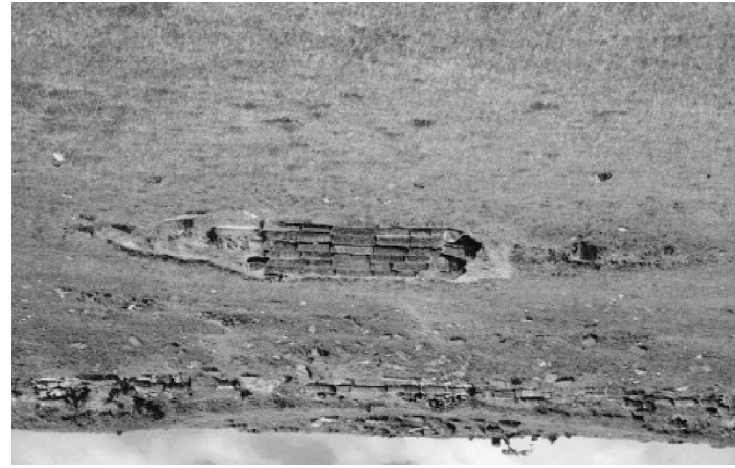

Fotografía 3. Muro frontal y escalinatas de la segunda plataforma. Fuente: Daniel Morales. 1996.

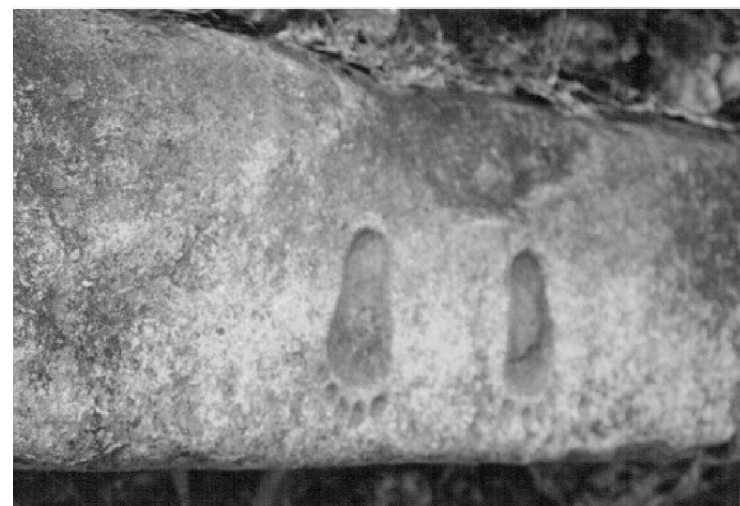

Fotografía 5. La piedra del rastro o de los pies tallados. Fuente: Daniel Morales. 1996.

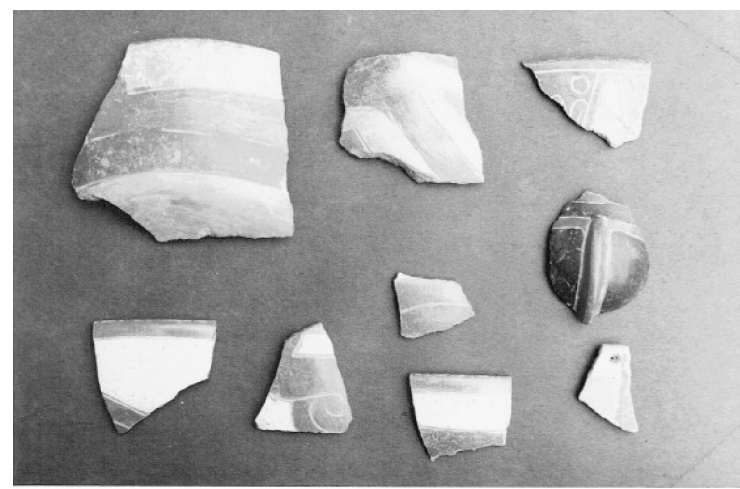

Fotografía 7. Cerámica de Pacopampa. Fuente: Daniel Morales. 1996.

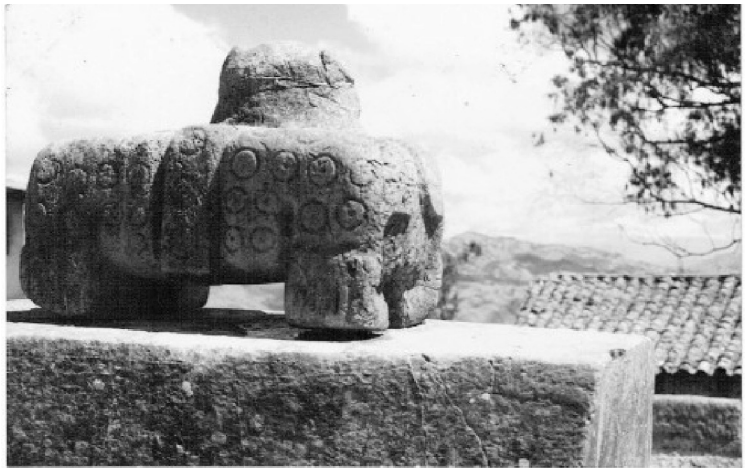

Fotografía 4. Monolito de felino-jaguar de la segunda plataforma. Fuente: Daniel Morales. 1996.

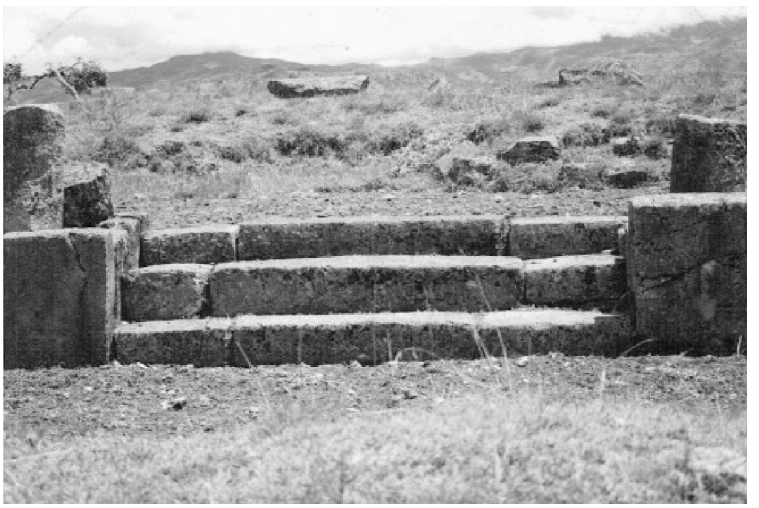

Fotografía 6. Escalinatas de la plaza hundida de la tercera plataforma. Fuente: Daniel Morales. 1996.

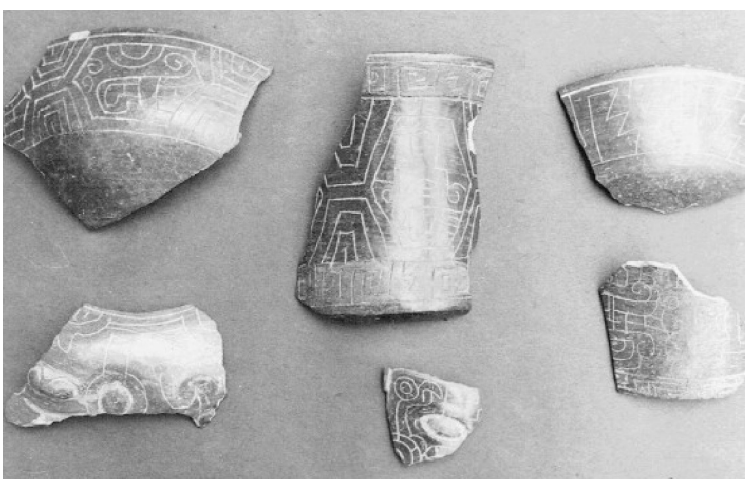

Fotografía 8. Cerámica de Pacopampa. Fuente: Daniel Morales. 1996.

- La fase Pacopampa Expansivo de Morales correspondería a las fases Pacopampa C y D de Fung y a la fase Pacopampa Chavín de Rosas y Shady. ${ }^{9}$

En el 2005, se llevó a cabo un convenio entre la UNMSM y el Museo Nacional de Etnología de Japón con el objeto de continuar con las investigaciones en el sitio arqueológico de Pacopampa. El convenio reconoce la dirección en el Dr. Yuji Seki y el arqueólogo Daniel Morales.

$9 \quad$ Seki y Morales 2014: 9-11 


\section{Otros estudios arqueológicos en el Seminario de Historia Rural Andina (1975-20o6)}

En el SHRA, se han publicado estudios arqueológicos sobre el Cusco, Junín, Puno, Huánuco y Lima. Además de la descripción de los sitios arqueológicos, estos estudios son de carácter multidisciplinario realizando una adecuada utilización de la Historia, Geografía, Antropología, etnohistoria, etnobotánica, entre otros. No obstante, los arqueólogos Daniel Morales y Jaime Miasta como investigadores del área de arqueología en el SHRA han marcado las líneas de investigación. Sus investigaciones se abocaron al tema andino y amazónico; por ejemplo, el estudio de figuras iconográficas resaltantes en piezas de cerámica, piedra o madera que se relacionó con los conceptos de arte, vinculadas además al trabajo de arte popular colonial del SHRA.

Daniel Morales fue investigador del SHRA entre los años 1972-1986, realizando innumerables viajes a Pacopampa, donde reunió una variedad de datos, que posteriormente formaría parte de su tesis de licenciatura. En la actualidad es codirector del Proyecto Arqueológico de Pacopampa y destacado exponente de las investigaciones arqueológicas de la selva amazónica. Una de sus primeras publicaciones fue Seminario arqueológico $n^{\circ} 1$ (1977) donde presenta los estudios preliminares de tres proyectos dentro del programa arqueológico del SHRA. El primero es el proyecto "Arqueología de la superficie del área de Tacabamba" (Pacopampa, Cajamarca, 1975), donde señala la influencia Wari-Tiahuanacoide en la estructura en forma de torres. Estas aparentemente no solo sirvieron como recintos funerarios, sino que tuvieron otras funciones como el de área doméstica, por ejemplo. Además, formaban hipotéticamente parte del Intermedio Temprano. ${ }^{10}$ La segunda investigación, "Excavaciones en las salinas de San Blas, Junín” (Junín, 1974), corresponde al período Formativo, donde se sostiene que el uso de la sal fue un factor determinante de transición de una economía de caza a una de agricultura incipiente. Por último, la investigación "Excavaciones en el pozo $\mathrm{N}^{\circ} 1$ del abrigo rocoso de Ushcomachay" (valle de Telarnioc, km 18, Junín, 1972), realiza un balance del abrigo rocoso y describe los registros arqueológicos como la cerámica de Fase Inicial, Formativo Medio e Intermedio Temprano.

Morales en Hacia las rutas de Vilcabamba, último reducto de resistencia incaica (1979), realiza un informe detallado de prospección del último reducto inca que resistió la invasión española hasta fines del siglo XVI. La ruta de estudio comprendió los sitios arqueológicos de Rosaspata, Nusta hispana y Espíritu Pampa. Esta es una guía de cómo fue su visita y prospección de los sitios arqueológicos.

Como parte de sus trabajos de campo, Morales publicó, Los alfareros de Huánuco (1981) donde realiza un estudio descriptivo de la alfarería tradicional de Huánuco, sus técnicas, características y el proceso de su producción.

En Tambor de Nazca (1982), Morales prueba que el uso de tambores en el área andina dataría de épocas pre cerámicas. Estos tambores corresponden a las culturas Vicus, Moche y Nazca. Morales precisa el material usado para los tambores (maguey, mates y arcilla), su uso y funcionamiento que no solo se asocia al arte natural sino también tienen carácter mágico religioso, festivo familiar, político y militar. Este interés por los tambores lleva al trabajo colectivo de Morales con Roel Josafat, Jorge Silva y José Yamunaqué, Tambores Andinos (1982). Este es un estudio sobre los instrumentos musicales prehispánicos y en particular sobre el uso y funciones del tambor. Se ubica su procedencia entre el Intermedio Temprano (400 a.c.-600 d.c.) e Intermedio Tardío (1100-1400 d.c). Además, se trabaja en dos partes; el primero de ellos es tambor de Pandanche (Cajamarca) y el segundo es el tambor Nazca (Ica).

$10 \quad$ Morales 1977: 4 
Jaime Miasta quien trabajó en el SHRA entre los años 1975-2001, realizó investigaciones en la selva peruana, proporcionando datos importantes en un área de estudios poco desarrollado por la Arqueología. Asimismo, muestra interés por el área andina. Años más tarde, asume la dirección del SHRA (2000-2001). En el 2005, realiza una exposición sobre Pacopampa donde mediante láminas presenta los resultados obtenidos del sitio arqueológico. ${ }^{11}$

Uno de los primeros libros de Miasta es El alto amazonas. Arqueología de Jaén y San Ignacio (1979), basado en los resultados de una serie de trabajos de campo en el sector Nor Oriente peruano (1977). Miasta, realizó un levantamiento fotográfico en la región, y topográfico en los sitios de Cerezal, Tocaquillo, Michinal, Faical y San Ignacio. Además, facilitó la comprensión de los complejos agrícolas vegetativos del Noroeste y la zona Septentrional. Asimismo, detalla el marco geográfico y el panorama bio cultural. Por último, presenta los mapas de la zona de Michinal, Cerezal y otros sitios, láminas de perfiles estratigráficos de suelos y de cerámica, reconoce la flora, fauna y figuras humanizadas del sector.

Miasta en Mamac decorada prehispánica (1981) aporta al conocimiento de la función y usos que habrían cumplido tres piezas de caña (Guadgua Kunth) que probablemente fueron formas primigenias de los keros Incas (vasos ceremoniales de madera y forma triangular) que presentan unidad en el diseño y diferencias particulares. El autor les denomina mamac, usando la voz quechua para nombrar a los keros. El empleo de la caña además habría cumplido varias funciones de uso: canales de irrigación, depósitos de agua o vasos ceremoniales de sacrificio y celebraciones asociadas a la fertilidad de la tierra. Sin embargo, dicho objeto arqueológico no ha sido contextualizado, por lo tanto las características que le proporciona el autor es sobre todo ritual.

Miasta en Ullquis, (1982) describe una figura de camélido tallada y pulida en madera dura probablemente de caoba o cedro nicaragüense. Esta es relacionada con figuras geométricas procedentes del Formativo y Horizonte Tardío. Según el autor sería un amuleto; sin embargo, no ha sido contextualizado.

Uno de los estudios más importantes de Miasta es Arqueología histórica en Huarochirí. Santo Domingo de los olleros, San José de los Chorrillos y San Lorenzo de Quinti (1985 y 1986). Miasta realiza un estudio minucioso de la cerámica de Olleros, la cerámica vidriada en los contextos pos incaico, centrado en tres puntos geográficos de la provincia de Huarochirí. Esta investigación arqueológica establece datos comparativos entre la técnica foránea y tradicional, gracias al uso de la termoluminiscencia. En el primer tomo su estudio se centra en el pueblo de Santo Domingo de Olleros, en el segundo, estudia los pueblos de San José de los Chorrillos y San Lorenzo de Quinti, provincia de Huarochirí (Lima).

Miasta publicó también el Inventario y catastro de monumentos arqueológicos del valle de Huaura (1986) donde detalla un registro de 131 yacimientos arqueológicos, situados en el sector medio del valle de Huaura (entre el puente de Huaura y el pueblo de Sayán). Miasta realiza una descripción de los sitios con fotografías, planos, dibujos, además del empleo de toponimias entre otros, obteniendo un cuadro general numerario y porcentual de los tipos por sitio como por ejemplo pirámides, montículos ciudadelas, fortines, poblados, viviendas, cementerio-tumbas, refugios, patios, terrazas plataformas, cercados, recintos, corrales, pozos, muros, caminos, pozos públicos, canales y templetes. ${ }^{12}$

11 Exposición Centro Ceremonial de Pacopampa: octubre 28-diciembre 23 de 2005, curadores: Jaime Miasta Gutiérrez y Miguel Enrique Gil Meza, como parte del trabajo anual del SHRA, directora Nanda Leonardini.

12 Andazabal 2006: 73 
Por último, Miasta alternó sus trabajos de Arqueología con la de hacer traducciones del inglés al español de artículos y libros sobre arqueología como los 31 volúmenes publicados en la serie Lecturas de Emilio Choy (1977-2009). Esta labor fue muy importante porque permitió el acceso de investigaciones novedosas a los estudiantes universitarios.

Como ya se mencionó el SHRA publicó estudios arqueológicos de investigadores procedentes de otras instituciones con el objetivo de presentar nuevas evidencias y fomentar el debate. En esta última sección se reseñará cada una de estas obras.

Las investigaciones de Jane Wheler Pires, Ramiro Matos y Edgardo Pires Ferreira en su Informe del programa de arqueología (1975) contiene resultados de las investigaciones arqueológicas del departamento de Puno dirigidas por el arqueólogo Ramiro Matos en la década de 1970. Es la primera colección osteológica de etno zoología andina que fue posible gracias a la UNMSM y la invalorable colaboración del Instituto Veterinario de Investigaciones Tropicales y de Altura (IVITA). Además, el Centro Nacional de Camélidos Americanos, estación principal de altura de la Raya (Puno) fue el lugar principal donde se realizaron los estudios de paleoetnozoología, gracias a ello se dio la creación del laboratorio de paleo etnobotánica y paleoetnozoología, presentado por Jane Wheler Pires, Ramiro Matos Mendieta y Edgardo Pires Ferreira. Un dato importante de los autores es que proponen que el estudio de plantas y animales ayudarán a vislumbrar las evidencias que se tiene de las culturas prehispánicas, con ello se podrá clasificar los especímenes que se obtengan de las excavaciones; asimismo, conocer la procedencia de estos.

En 1976 se reedita el libro Introducción de la Historia Antigua del Perú de Julio C. Tello. Publicado originalmente en 1921, Tello describe la evolución del hombre peruano antes de la invasión española donde postula teorías poligenista y monogenista de la primitiva civilización peruana. Además, analiza la sociedad indígena desde una perspectiva de unidad nacional, es decir, entendiendo a las diversas culturas (Nazca, Mochica, Chimú, etc.) como derivadas de un solo tronco, del cual parten otras tantas ramificaciones, con características propias que las distinguen en cuanto a composición étnica, lengua, religión, geografía, etc. Este libro se dio a conocer gracias a la primera promoción de estudiantes de Arqueología de la UNMSM, que tomó el nombre de Emilio Choy.

Tom Dillehay, publicó un informe titulado Características Urbanas de Huancayo Alto (1977), presentado en el II Congreso Peruano del Hombre y la Cultura Andina (Trujillo, 1974). Dillehay menciona las características urbanas de Huancayo Alto, con el propósito de visualizar las variadas funciones del sitio arqueológico perteneciente al Intermedio Tardío en el valle de Chillón con influencia del Altiplano. Además, los rasgos urbanos considerados en la cronología Pre Incaica presentan diferentes áreas como almacenes, sector administrativo, residencias de elites, sistema defensivo y un cementerio. Existen muchos aspectos en cuanto a las funciones de la arquitectura, como la centralización en esta área; por último, propone el urbanismo como una característica propia de las fuertes tensiones de organización dentro del contexto sociopolítico y los sucesos de las sociedades.

Ana Soldi en su libro titulado Chacras Excavadas en el Desierto (1979) presenta un estudio del desarrollo agrícola en el desierto costero peruano. En tal sentido, detalla las ventajas y desventajas del cultivo en chacras excavadas, reconoce el empleo de puquios y huachaques (costa norte), pozos (Huanchaco), canchones (Tarapacá) y mahames (Ica), que tuvieron auge en el período Intermedio Tardío. Además, menciona la importancia de las chacras hundidas en el desarrollo agrícola. Por último, emplea varias disciplinas para su estudio, resalta las evidencias arqueológicas en los valles de Virú y Chan Chan (costa norte), Chilca (costa central), pampas de Villacurí y Lanchas (entre Pisco e Ica), como también desde Arequipa hasta Tarapacá. 
Alberto Rex Gonzales en El Arte, estructura y arqueología (1979), realiza un estudio iconográfico de las sociedades agro alfareras del noroeste argentino. En la década de 1970, los estudios iconográficos en el área de América Sur eran limitados: los investigadores tuvieron falencias al interpretar la iconografía de las culturas por falta de información sobre cronología, complejos culturales o el modo de subsistencia de los pueblos desaparecidos. Rex Gonzales propone el concepto de dualidad reflejado en las iconografías andinas, evidencia encontrada en sitios arqueológicos del Noroeste argentino. Este tema ha estado presente durante milenios; desde las esfinges faraónicas, la serpiente emplumada de Mesoamérica, los leones asirios hasta los diablos y ángeles de las iglesias. ${ }^{13}$ Asimismo, propone una división para el estudio de la iconografía: piezas con rasgos mixtos (felino-humanos), piezas con rasgos múltiples (felino-antropomorfos u ornitomorfos), mezcla (felino-humano) por actitud postural, imágenes duales realistas en una misma pieza, dualidad de oposición binaria como expresión de otros conceptos, dualidad en una misma imagen (figuras anatrópicas), dualidad por representación bipartida, dualidad por oposición de figuras antípodas. Por último, menciona la importancia del complejo de transformación específicamente relacionado con los alucinógenos que probablemente fueron utilizados por los pueblos del Noroeste argentino, ya que existe evidencia de morteros de piedra, tabletas de madera, entre otros. ${ }^{14}$

Tomas Gallarday, en su informe Arcillas de la Costa Central Peruana (Cuenca del rio Chancay) (1982), realiza estudios teóricos de geomorfología, sedimentología, además de un muestreo general del yacimiento ubicado en la cuenca de Chancay. Dicho análisis arroja resultados de uso, propiedades, aplicación del tipo de arcillas como también el origen del yacimiento que es fluvial eólico.

En Junín, Arturo Mallma, realiza un trabajo titulado Introducción a la Arqueología e Historia de los Xauxas Wankas (1996). Consta de un resumen secuencial de la historia y arqueología de los Xauxas, en su proceso de surgimiento del grupo étnico Wanka. Es una visión panorámica del proceso histórico, desde las primeras ocupaciones formativas hasta la construcción y diseño planiamétrico de la ciudad administrativa inca. Además, incluye esquemas cronológicos de los estudios de diversos científicos nacionales y extranjeros, como también un detallado estudio secuencial de la cerámica del valle del Mantaro.

El arqueólogo Manuel Aguirre Morales en su libro Los andenes del río Ayaviri-Yauyos (2005) realiza un estudio de la sub cuenca del Ayaviri, Yauyos del valle alto del río Mala-Lima, desde un ordenamiento ambiental por parte de la ONERN y del Ministerio de Agricultura durante las décadas de 1970 y 1980. Presenta las características actuales de la comunidad campesina Jesús de Ayaviri y describe la problemática asociada a los andenes regados. Discute categorías como andenes y terrazas, así como las implicancias sociales de su construcción en el pasado y propone algunas hipótesis para el trabajo arqueológico. Finalmente, plantea una reflexión acerca de la recuperación de los andenes hoy en día, sobre todo para las comunidades campesinas de las provincias del departamento de Lima. ${ }^{15}$ Es una investigación es un aporte al estudio de los andenes, trabajo que puede ser aplicado para otros sectores del país, por la similitud del caso.

Aguirre Morales en otro libro titulado Arqueología e ideología en el Perú (2006) presenta antecedentes y planteamientos de la Arqueología social en el Perú. Realiza estudios desde la perspectiva marxista y como ésta pretende explicar la historia de las sociedades precolombinas, además de las relaciones del contexto socio-político y económico del Perú en el siglo XX y el discurso so-

13 Rex Gonzales. 1979: 5

14 Rex Gonzales. 1979: 50

15 Pinto Honorio 2001: 40. 
ciológico de arqueólogos peruanos y extranjeros que determinan una relación entre Arqueología, ideología y política en el Perú.

\section{Conclusiones}

Las publicaciones sobre arqueología en el contexto de las publicaciones del SHRA no son numéricamente importantes: 59 siendo la mayoría, 31, de la serie Lecturas escogidas por Emilio Choy. Sin embargo, desde los inicios del SHRA la investigación arqueológica ha sido importante. Ello es evidente con el interés e impulso al estudio del sitio arqueológico de Pacopampa que ha generado una serie de publicaciones de índole científico, que muestran a su vez la capacidad de generar información de manera correlativa, con capacidad de gestión al iniciar los proyectos de excavación. Además, ha sido para muchos arqueólogos, un primer acercamiento a un sitio arqueológico tan complejo perteneciente al Formativo, teniendo en cuenta por la década de 1960 se conocía muy poco sobre Pacopampa y el Formativo.

Las investigaciones dieron como resultado una variedad de publicaciones por reconocidos arqueólogos como Hermilio Rosas, Ruth Shady, Rosa Fung, Julián Santillana, Isabel Flores, Daniel Morales, Jaime Miasta, Peter Kaulicke, entre otros. Asimismo, años más tarde se continúan los estudios en Pacopampa, ya contando con el convenio Museo Nacional de Etnología de Japón y la Universidad Nacional Mayor de San Marcos, (2005) hasta la actualidad.

Por otro lado, se iniciaron una serie de trabajos de campo en otros sectores del país como Cusco, Puno, Huánuco, Junín y Lima; la información ha servido como base y modelo para otras investigaciones. La producción académica en el SHRA, ha dejado alcances para las investigaciones posteriores, a su vez ha mostrado una capacidad de gestión e investigación en el área de la arqueología con relación al legado cultural en diferentes aspectos de las sociedades prehispánicas.

\section{Bibliografía}

Andazabal, Rosaura (2006). Publicaciones Seminario de Historia Rural Andina (1968-2000). Lima: Seminario de Historia Rural Andina, Universidad Nacional Mayor de San Marcos.

Bueno, Alberto, (2010). “Julio C. Tello y la arqueología del Perú”. Investigaciones sociales, 14, (25), pp. 17-46.

Dillehay, Tom (1977). Características urbanas de Huancayo Alto. Lima: Seminario de Historia Rural Andina, Universidad Nacional Mayor de San Marcos.

Flores, Isabel y Santillana, Julián (1975). Excavaciones en el Mirador: Pacopampa. Prospección arqueológica en Pacopampa. Lima: Seminario de Historia Rural Andina, Universidad Nacional Mayor de San Marcos.

Gallarday, Tomas (1982). Arcillas de la costa central peruana (cuenca del rio Chancay). Lima: Seminario de Historia Rural Andina, Universidad Nacional Mayor de San Marcos.

Kaulicke, Peter (1975). Pandanche: Un caso del formativo en los andes de Cajamarca. Lima: Seminario de Historia Rural Andina, Universidad Nacional Mayor de San Marcos.

Kaulicke, Peter (1976). El formativo en Pacopampa. Lima: Seminario de Historia Rural Andina, Universidad Nacional Mayor de San Marcos.

Miasta, Jaime (1979). El alto Amazonas. Arqueología de Jaén y San Ignacio, Perú. Lima: Seminario 
de Historia Rural Andina, Universidad Nacional Mayor de San Marcos.

Miasta, Jaime (1981). Mamac decorada prehispánica. Lima: Seminario de Historia Rural Andina, Universidad Nacional Mayor de San Marcos.

Miasta, Jaime (1982). Ullquis. Lima: Seminario de Historia Rural Andina, Universidad Nacional Mayor de San Marcos.

Miasta, Jaime (1985). Arqueología Histórica de Huarochirí: Santo Domingo de los Olleros, San José de los Chorrillos y San Lorenzo de Quinti. Tomo I, Lima, Seminario de Historia Rural Andina, Universidad Nacional Mayor de San Marcos.

Miasta, Jaime (1986). Arqueología Histórica de Huarochirí: Santo Domingo de los Olleros, San José de los Chorrillos y San Lorenzo de Quinti. Tomo II, Lima, Seminario de Historia Rural Andina, Universidad Nacional Mayor de San Marcos.

Morales, Daniel (1977). Seminario arqueológico $N^{\circ} 1$. Lima: Seminario de Historia Rural Andina, Universidad Nacional Mayor de San Marcos.

Morales, Daniel (1979). Hacia las rutas de Vilcabamba, último reducto de resistencia incaica. Lima: Seminario de Historia Rural Andina, Universidad Nacional Mayor de San Marcos.

Morales, Daniel (1980). El arte erótico en Pacopampa. Lima: Seminario de Historia Rural Andina, Universidad Nacional Mayor de San Marcos.

Morales, Daniel (1980). El Dios felino en Pacopampa. Lima: Seminario de Historia Rural Andina, Universidad Nacional Mayor de San Marcos.

Morales, Daniel (1981). Los Alfareros de Huánuco. Lima: Seminario de Historia Rural Andina, Universidad Nacional Mayor de San Marcos.

Morales, Daniel (1982). Tambor Nazca. Lima: Seminario de Historia Rural Andina, Universidad Nacional Mayor de San Marcos.

Pinto, Honorio (2011). Seminario de Historia Rural Andina. Publicaciones 2001-2010. Lima: Seminario de Historia Rural Andina, Universidad Nacional Mayor de San Marcos.

Rex, Alberto (1979). Arte, estructura y Arqueología. Lima: Seminario de Historia Rural Andina, Universidad Nacional Mayor de San Marcos.

Roel, Josafat; Silva, Jorge; Morales, Daniel y Yamunaqué, José (1982). Tambores Andinos. Lima: Seminario de Historia Rural Andina, Universidad Nacional Mayor de San Marcos.

Rosas, Hermilio y Shady, Ruth (1970). Pacopampa: Un centro Formativo en la sierra norperuana. Lima: Seminario de Historia Rural Andina, Universidad Nacional Mayor de San Marcos.

Seki Yuji y Morales, Daniel (2014). Informe del Proyecto Arqueológico Pacopampa, Cajamarca. Archivo del Fondo del Seminario de Historia Rural Andina.

Soldi, María (1979). Chacras excavadas en el desierto. Lima: Seminario de Historia Rural Andina, Universidad Nacional Mayor de San Marcos.

Tello, Julio (1976). Introducción a la historia antigua del Perú (1921). Lima: Seminario de Historia Rural Andina, Universidad Nacional Mayor de San Marcos.

Tello, Julio (1977). La investigación Científica. Lima: Seminario de Historia Rural Andina, Universidad Nacional Mayor de San Marcos.

Wheler Pires, Jane; Matos, Ramiro y Pires Ferreira (1975). Informe del Programa de Arqueología. Lima: Seminario de Historia Rural Andina, Universidad Nacional Mayor de San Marcos.

Fecha de recepción: 29/VIII/2016

Fecha de aceptación: 30/IX/2016 